\title{
Disruption of doubly uniparental inheritance of mitochondrial DNA in hybrid mussels (Mytilus edulis $\times$ M. galloprovincialis)
}

\author{
AR Wood ${ }^{1,3}$, G Turner ${ }^{1}$, DOF Skibinski ${ }^{2}$ and AR Beaumont ${ }^{1}$ \\ ${ }^{1}$ School of Ocean Sciences, University of Wales Bangor, Menai Bridge, Anglesey, Wales LL59 5EY, UK; ${ }^{2}$ School of Biological Sciences, \\ University of Wales Swansea, Singleton Park, Swansea, Wales SA2 8PP, UK
}

\begin{abstract}
Blue mussels of the genus Mytilus have an unusual mode of mitochondrial DNA inheritance termed doubly uniparental inheritance (DUI). Females are homoplasmic for the $\mathrm{F}$ mitotype which is inherited maternally, whereas males are heteroplasmic for this and the paternally inherited $M$ mitotype. In areas where species distributions overlap a varying degree of hybridization occurs; yet genetic differences between allopatric populations are maintained. Observations from natural populations and previous laboratory experiments suggest that DUI may be disrupted by hybridization, giving rise to heteroplasmic females and homoplasmic males. We carried out controlled laboratory crosses between Mytilus edulis and $M$. galloprovincialis to produce pure species and hybrid larvae of known parentage. DNA
\end{abstract}

markers were used to follow the fate of the $F$ and $M$ mitotypes through larval development. Disruption of the mechanism which determines whether the $\mathrm{M}$ mitotype is retained or eliminated occurred in an estimated $38 \%$ of $M$. edulis $\times M$. galloprovincialis hybrid larvae, a level double that previously observed in adult mussels from a natural $M$. edulis $\times M$. galloprovincialis hybrid population. Furthermore, reciprocal hybrid crosses exhibited contrasting types of DUI disruption. The results indicate that disruption of DUI in hybrid mussels may be associated with increased mortality and hence could be a factor in the maintenance of genetic integrity for each species.

Heredity (2003) 91, 354-360. doi:10.1038/sj.hdy.6800345

Keywords: Mytilus edulis; Mytilus galloprovincialis; hybridization; mitochondrial DNA; doubly uniparental inheritance

\section{Introduction}

Mussels of the Mytilus edulis complex (M. edulis, M. galloprovincialis and $M$. trossulus) are found at temperate latitudes throughout the Northern and Southern hemispheres (McDonald et al, 1991). Hybridization occurs to varying degrees where the species distributions overlap (Skibinski et al, 1983; McDonald et al, 1991; Gosling, 1992) and yet the taxa seem to remain morphologically and genetically distinct in areas of allopatry. The largest and most studied zone of Mytilus hybridization is between M. edulis and M. galloprovincialis, extending over more than $1000 \mathrm{~km}$ from the southern Atlantic coast of France to the British Isles (Skibinski et al, 1983; Sanjuan et al, 1994).

It is generally thought that, in terrestrial species, selection against hybrids is more important than environmental conditions favouring the parental types in maintaining hybrid zones (Barton and Hewitt, 1989). However, for M. edulis and M. galloprovincialis, there is a variety of evidence indicating that the fitness of hybrid mussels is not inferior to that of parental taxa (Gardner, 1994). Little is known about how hybrid zones are maintained in this group of taxa, which have a prolonged

Correspondence: AR Wood, School of Biological Sciences, Victoria University of Wellington, PO Box 600, Wellington, New Zealand. E-mail:ann.wood@vuw.ac.nz

${ }^{3}$ Current address: School of Biological Sciences, Victoria University of Wellington, PO Box 600, Wellington, New Zealand

Received 29 March 2003 planktonic larval stage facilitating dispersal over great distances. Several studies have found no evidence for gamete incompatibility between $M$. edulis and M. galloprovincialis (Lubet et al, 1984; Beaumont et al, 1993; our unpublished data). However, Bierne et al (2002) demonstrated that, where gamete competition is possible, intraspecific fertilization occurs preferentially to hybridization. It remains unknown whether significant gamete competition occurs in natural spawning events. Furthermore, given the degree of hybridization observed in natural populations, gamete preference alone is not a strong enough mechanism to maintain the genetic differences that exist between these taxa (Bierne et al, 2002). It is likely that postzygotic factors in some way limit the degree of introgression where species distributions overlap.

Mussels of the M. edulis complex have an unusual mode of mitochondrial DNA (mtDNA) inheritance (Skibinski et al, 1994; Zouros et al, 1994), termed doubly uniparental inheritance (DUI). Females are homoplasmic for the F mitotype which is inherited maternally, whereas males are heteroplasmic for this and the paternally inherited M mitotype. However, the gametes of both sexes are homoplasmic, in females for $\mathrm{F}$ and in males for $\mathrm{M}$. It is thought that sperm mitochondria enter the egg at fertilization (Longo and Anderson, 1969) and that the M mitotype is eliminated in larvae destined to become female mussels at some point between 18 and $48 \mathrm{~h}$ after fertilization (Sutherland et al, 1998; our unpublished data). 
The doubly uniparental mtDNA inheritance in Mytilus and the tissue-specific distribution of the $M$ and $F$ mitotypes in males (Garrido-Ramos et al, 1998) may impose greater requirements for compatibility between nuclear and mitochondrial genomes than in species with standard maternal inheritance (Saavedra et al, 1996). For introgression to occur, compatibility of one species' nuclear DNA with the other species' mtDNA would be required in addition to compatibility of one species' $F$ mitotype with the other species' $M$ mitotype in hybrid males (Saavedra et al, 1996). If the system of DUI is disrupted by hybridization, then the level of introgression among Mytilus taxa may be affected, which could be an important factor in the maintenance of genetic integrity for each taxon (Rawson et al, 1996).

Several studies of DUI in Mytilus hybrids have found male mussels homoplasmic for the $\mathrm{F}$ mitotype and female mussels heteroplasmic for both $\mathrm{F}$ and $\mathrm{M}$ mitotypes, providing evidence that disruption of DUI occurs. Disruption of DUI appears to be widespread in $M$. galloprovincialis $\times M$. trossulus hybrids, but there is little evidence for disruption in $M$. edulis $\times M$. galloprovincialis hybrids (Rawson et al, 1996). Disruption of DUI has also been detected in laboratory-produced hybrids between M. edulis and M. trossulus (Zouros et al, 1994). This previous work has concentrated largely on adult mussels from natural populations, where the precise genetic and geographic background of a hybrid individual is uncertain. Laboratory-based hybridizations offer an opportunity to study DUI in pure species and hybrid larvae of known provenance.

Where there is disruption of DUI, homoplasmic males may arise because of a failure in either the inheritance or retention of the $\mathrm{M}$ mitotype. Heteroplasmic females must presumably arise from a breakdown in the mechanism that would normally cause elimination of the $M$ mitotype. In the majority of cases where sex ratio has been examined in laboratory crosses, half-sib families from the same mother have similar sex ratios. This has been demonstrated for pure species $M$. edulis families (Kenchington et al, 2002), M. galloprovincialis families (Saavedra et al, 1997) and for comparisons between pure species $M$. edulis and hybrid $M$. edulis $\times M$. trossulus families (Zouros et al, 1994). Furthermore, it is a feature of the DUI system that in normal families the proportion of larvae with the $\mathrm{M}$ mitotype should reflect the sex ratio (Zouros et al, 1994; Saavedra et al, 1997). If a pure species and a hybrid family of larvae share the same mother, disruption of DUI in the hybrid family might result in a difference in the proportion of larvae with the $M$ mitotype from that observed in the pure species family. The objective of this study is to assess the resilience of DUI to hybridization between $M$. edulis and M. galloprovincialis, by comparing the inheritance and elimination of the $\mathrm{M}$ mitotype in pure species and hybrid larvae.

\section{Materials and methods}

Adult M. edulis were obtained from Loch Etive on the west coast of Scotland and M. galloprovincialis were collected near Montpellier on the Mediterranean coast of France. These populations are believed to be pure species based on previous allozyme analysis (Skibinski et al, 1983; McDonald et al, 1991; Gosling, 1992). Mussels were transported live to Menai Bridge and held in an approved flowing seawater quarantine system at approximately $6^{\circ} \mathrm{C}$, with added microalgae, until required for hybridization trials.

Three full reciprocal crosses were carried out between June and August 2000, each comprising intra- and interspecific crosses between one female and one male of each species. The protocol was designed to enable comparison of pure species and hybrid families that share either a female or male parent. For each trial, approximately 50 mussels from each species were removed from the holding tanks and induced to spawn by injection of $0.5 \mathrm{M} \mathrm{KCl}$ into the mantle cavity, followed by a period of $1-2 \mathrm{~h}$ out of water at $18-20^{\circ} \mathrm{C}$. Each mussel was then placed in a separate glass jar of $0.2-\mu \mathrm{m}$-filtered and UV-treated seawater (FSW) so that gametes could be collected. Once spawning had occurred, parent mussels were selected on the basis of morphological normality of eggs or activity of sperm. Fertilizations were carried out by mixing eggs from individual females with sperm from individual males in separate containers, taking great care to avoid cross-contamination. The sperm to egg ratio was between 10 and 100 to 1 . Embryos were transferred into 11 glass crystallizing dishes at a density of 100000 per dish (two replicate dishes per family) and left at $14^{\circ} \mathrm{C}$ for $72 \mathrm{~h}$ to develop to the first shelled veliger stage. Samples of adductor muscle from each parent, and of larvae from each family at 3 and $72 \mathrm{~h}$ after fertilization, were preserved in $70 \%$ ethanol in FSW.

DNA analysis was carried out between 1 and 12 months after sampling. For each adult mussel, adductor muscle tissue (approx. $3 \mathrm{~mm}^{3}$ ) was macerated with sterile sand in $300 \mu \mathrm{CTAB}$ buffer $(100 \mathrm{mM}$ Tris- $\mathrm{HCl}$ $\mathrm{pH} 8,1.4 \mathrm{M} \mathrm{NaCl}, 20 \mathrm{mM}$ EDTA, 2\% CTAB) and then incubated with $0.15 \mathrm{mg}$ proteinase $\mathrm{K}$ at $55^{\circ} \mathrm{C}$ for $1-2 \mathrm{~h}$. DNA was extracted by a phenol:chloroform method based on that of Sambrook et al (1989). Individual larvae were washed and isolated in $1 \mu \mathrm{l}$ of FSW using a micropipette and transferred to $0.5 \mathrm{ml}$ sterile microtubes containing $15 \mu \mathrm{l}$ of a lysis solution containing proteinase $\mathrm{K}$ (Sutherland et al, 1998). Incubation at $37^{\circ} \mathrm{C}$ for $1.5 \mathrm{~h}$ was followed by $10 \mathrm{~min}$ at $99^{\circ} \mathrm{C}$ to inactivate proteinase $\mathrm{K}$, and the resulting lysate was used as a template for PCR amplification.

For each individual, two separate PCRs were carried out: one using F mitotype-specific primers and another using $\mathrm{M}$ mitotype-specific primers. The $\mathrm{F}$ mitotypespecific PCR primers 5'-ATGTACCAGGTCCAAGTCCG TG-3' and 5'-CACATACACTAAGCACCACAATG-3' (Stewart et al, 1995; Sutherland et al, 1998) were used to amplify a $753 \mathrm{bp}$ fragment of the COIII gene from both species and their hybrids. The reaction mixture contained $10 \mathrm{mM}$ Tris- $\mathrm{HCl}$ (pH 8.3), $50 \mathrm{mM} \mathrm{KCl}, 5 \mathrm{mM}$ $\mathrm{NH}_{4} \mathrm{Cl}, 3 \mathrm{mM} \mathrm{MgCl}, 0.2 \mathrm{mM}$ of each $\mathrm{dNTP}, 0.4 \mu \mathrm{M}$ of each primer and 1.25 U Taq DNA polymerase in a $25 \mu \mathrm{l}$ volume. The temperature cycle consisted of an initial denaturation period of $4 \mathrm{~min}$ at $94^{\circ} \mathrm{C}$ followed by 40 cycles of $30 \mathrm{~s}$ at $94^{\circ} \mathrm{C}, 90 \mathrm{~s}$ at $59^{\circ} \mathrm{C}, 30 \mathrm{~s}$ at $72^{\circ} \mathrm{C}$ and a final extension period of $4 \mathrm{~min}$ at $72^{\circ} \mathrm{C}$. For detection of the $\mathrm{M}$ mitotype, different primers were used depending on the species of the male parent of the family. For families with an $M$. edulis male parent, the $M$ mitotype-specific primers 5'-TGGAGTCGCTTTATTTATTTTATCTGA-3' and 5'-ATACTACAAACCACAGCCTCACTCATA-3' of Sutherland et al (1998) were used to amplify a $530 \mathrm{bp}$ fragment of the COIII gene. The reaction conditions were 
as given for the $\mathrm{F}$ mitotype-specific primers above, except that the $\mathrm{MgCl}_{2}$ concentration was $2 \mathrm{mM}$ and the annealing temperature was $63^{\circ} \mathrm{C}$. These primers did not amplify from the $M$. galloprovincialis used in this study. For families with an $M$. galloprovincialis male parent, the primers PR17 (5'-GCTTCTACACCTCTAGGACAC-3') and PR18 (5'-CTGCCC $(\mathrm{A} / \mathrm{T})(\mathrm{G} / \mathrm{A}) \mathrm{TGCAACTAAAT-}$ TAAC- $3^{\prime}$ ) of Rawson and Hilbish (1995) were used to amplify a $440 \mathrm{bp}$ fragment of the $16 \mathrm{~S}$ rRNA gene. The reaction mixture contained $10 \mathrm{mM}$ Tris- $\mathrm{HCl}(\mathrm{pH} 9.0)$, $50 \mathrm{mM} \mathrm{KCl}, 1.5 \mathrm{mM} \mathrm{MgCl}_{2}, 0.2 \mathrm{mM}$ of each dNTP, $0.4 \mu \mathrm{M}$ of each primer, $0.1 \%$ Triton $\mathrm{X}^{\circledR}-100$ and $1 \mathrm{U}$ Taq DNA polymerase in a $25 \mu \mathrm{l}$ volume. The initial denaturation period was $3 \mathrm{~min}$ at $94^{\circ} \mathrm{C}$, followed by 30 cycles of $20 \mathrm{~s}$ at $94^{\circ} \mathrm{C}, 20 \mathrm{~s}$ at $58^{\circ} \mathrm{C}, 45 \mathrm{~s}$ at $72^{\circ} \mathrm{C}$ and a final extension period of $3 \mathrm{~min}$ at $72^{\circ} \mathrm{C}$. F mitotype PCR products were electrophoresed on $1 \%$ agarose gels and stained with ethidium bromide. All M mitotype PCR products, plus any $F$ mitotype PCR products which gave negative results on agarose, were electrophoresed on $5 \%$ nondenaturing polyacrylamide gels and bands were visualized by a silver staining method (Skibinski et al, 1994).

The species identity of parents and larvae was confirmed using the Me15 and Me16 primers of Inoue et al (1995), as described in Wood et al (2003). Identity of the female parent of each family was confirmed for a subsample of larvae using a restriction fragment length polymorphism (RFLP) which distinguished F mitotype COIII gene PCR products from the different parents. F mitotype PCR product $(5 \mu \mathrm{l}$ from each parent or $10 \mu \mathrm{l}$ from each larva) was incubated at $37^{\circ} \mathrm{C}$ for $2.5 \mathrm{~h}$ with $3 \mathrm{U}$ of DdeI. The resulting fragments were electrophoresed on $2 \%$ agarose gels and stained with ethidium bromide. Matching of the RFLP pattern in the larvae with that of the appropriate female parent, together with the Me15/ 16 genotype, confirmed the family identity of each sample of larvae.

\section{Results}

Parents and larvae from 12 families were analysed for the presence of the $\mathrm{F}$ and $\mathrm{M}$ mitotypes. The $\mathrm{F}$ mitotype was detected in all 12 parents. The M mitotype was detected in all six male parents and also at a weak band intensity in two of the three $M$. galloprovincialis female parents. DNA was extracted from the eggs of these two female parents and analysed for the presence of the $F$ and $M$ mitotypes. In both cases, using polyacrylamide gel electrophoresis and silver staining, the F mitotype was detected but the $\mathrm{M}$ mitotype was not.

Table 1 shows the percentage of larvae in which the $\mathrm{F}$ and $\mathrm{M}$ mitotypes were detected for the 12 families. We expect to find both $\mathrm{F}$ and $\mathrm{M}$ mitotypes present in all larvae at $3 \mathrm{~h}$, but some reduced percentage of the $\mathrm{M}$ mitotype (related to the sex ratio) in $72 \mathrm{~h}$ larvae. For both the 3 and $72 \mathrm{~h}$ samples, the $\mathrm{F}$ mitotype was detected in almost all larvae (89-100\%). At $3 \mathrm{~h}$, the $\mathrm{M}$ mitotype was detected in most larvae, although a lower percentage (72\%) occurred in family 3 . As family 3 was a pure species M. galloprovincialis family, this difference cannot be due to hybridization affecting the inheritance of the $M$ mitotype. At $72 \mathrm{~h}$, the $\mathrm{M}$ mitotype was detected in 47 $68 \%$ of larvae from the pure species families, but this value ranged from 4 to $93 \%$ in the hybrid families.
Table 1 Occurrence of the F and M mitotypes in pure species and hybrid larvae from 12 Mytilus families at 3 and $72 \mathrm{~h}$ postfertilization

\begin{tabular}{|c|c|c|c|c|c|}
\hline $\begin{array}{l}\text { Family } \\
\text { number }\end{array}$ & $\begin{array}{l}\text { Parents } \\
(q \times \widehat{\sigma})\end{array}$ & $\begin{array}{l}\text { Family type } \\
\text { (pure species } \\
\text { or hybrid) }\end{array}$ & $N$ & $\begin{array}{c}\% \text { of larvae } \\
\text { with } F \\
\text { mitotype }\end{array}$ & $\begin{array}{c}\% \text { of larvae } \\
\text { with } M \\
\text { mitotype }\end{array}$ \\
\hline \multicolumn{6}{|l|}{$\begin{array}{l}\text { 3-h-old } \\
\text { larvae }\end{array}$} \\
\hline 1 & $\mathrm{E} \times \mathrm{E}$ & Pure & 33 & 94 & 88 \\
\hline 2 & $\mathrm{E} \times \mathrm{G}$ & Hybrid & 35 & 100 & 97 \\
\hline 3 & $G \times G$ & Pure & 32 & 100 & 72 \\
\hline 4 & $\mathrm{G} \times \mathrm{E}$ & Hybrid & 33 & 97 & 91 \\
\hline 5 & $\mathrm{E} \times \mathrm{E}$ & Pure & 18 & 89 & 94 \\
\hline 6 & $\mathrm{E} \times \mathrm{G}$ & Hybrid & 19 & 100 & 89 \\
\hline 7 & $\mathrm{G} \times \mathrm{G}$ & Pure & 20 & 95 & 100 \\
\hline 8 & $\mathrm{G} \times \mathrm{E}$ & Hybrid & 18 & 100 & 94 \\
\hline 9 & $E \times E$ & Pure & 25 & 100 & 100 \\
\hline 10 & $\mathrm{E} \times \mathrm{G}$ & Hybrid & 24 & 100 & 96 \\
\hline 11 & $G \times G$ & Pure & 25 & 96 & 100 \\
\hline 12 & $\mathrm{G} \times \mathrm{E}$ & Hybrid & 23 & 96 & 96 \\
\hline \multicolumn{6}{|l|}{$\begin{array}{l}\text { 72-h-old } \\
\text { larvae }\end{array}$} \\
\hline 1 & $\mathrm{E} \times \mathrm{E}$ & Pure & 34 & 94 & 59 \\
\hline 2 & $\mathrm{E} \times \mathrm{G}$ & Hybrid & 34 & 100 & 82 \\
\hline 3 & $G \times G$ & Pure & 33 & 97 & 64 \\
\hline 4 & $\mathrm{G} \times \mathrm{E}$ & Hybrid & 32 & 100 & 9 \\
\hline 5 & $\mathrm{E} \times \mathrm{E}$ & Pure & 30 & 100 & 50 \\
\hline 6 & $\mathrm{E} \times \mathrm{G}$ & Hybrid & 30 & 97 & 87 \\
\hline 7 & $G \times G$ & Pure & 30 & 100 & 60 \\
\hline 8 & $\mathrm{G} \times \mathrm{E}$ & Hybrid & 29 & 100 & 14 \\
\hline 9 & $\mathrm{E} \times \mathrm{E}$ & Pure & 28 & 96 & 68 \\
\hline 10 & $\mathrm{E} \times \mathrm{G}$ & Hybrid & 30 & 100 & 93 \\
\hline 11 & $\mathrm{G} \times \mathrm{G}$ & Pure & 30 & 100 & 47 \\
\hline 12 & $\mathrm{G} \times \mathrm{E}$ & Hybrid & 25 & 100 & 4 \\
\hline
\end{tabular}

$N=$ sample size, $\mathrm{E}=$ M. edulis, $\mathrm{G}=M$. galloprovincialis.

To test for any association between family type and proportion of larvae with the M mitotype, a Fisher exact test was used to compare the results for the two pure species families in each group and compare the results for each of the two pure species families with the hybrid families in each group for the 3 and $72 \mathrm{~h}$ samples (Table 2). There was no significant difference in the proportion of larvae with the M mitotype between pure M. edulis and pure $M$. galloprovincialis families at either 3 or $72 \mathrm{~h}$. This suggests that within each group, the two female parents produce families with similar sex ratios. Therefore, with the assumption that all the four families within each group can be expected to have similar sex ratios, all possible comparisons were made between pure species and hybrid families within each group.

For the $3 \mathrm{~h}$ samples, there were no significant differences in the proportion of larvae with the $M$ mitotype between pure species and hybrid families, with the exception of family 3 vs family 2 comparison (pure $M$. galloprovincialis vs $M$. edulis female $\times M$. galloprovincialis male). The proportion of larvae with the $M$ mitotype in family 3 was significantly less than that in family 2 at $3 \mathrm{~h}$. It is the pure $M$. galloprovincialis family (3), rather than the hybrid family (2), that differs from the biological expectation; so this significant result does not indicate any effect of hybridization on the inheritance of the $M$ mitotype. The lower proportion of $3 \mathrm{~h}$ larvae with the $\mathrm{M}$ mitotype in family 3 might suggest that elimination of the $\mathrm{M}$ mitotype had commenced before $3 \mathrm{~h}$, but is more 
Table $2 P$-values from Fisher exact test for independence of family and proportion of larvae with the M mitotype

\begin{tabular}{|c|c|c|c|}
\hline $\begin{array}{l}\text { Families compared } \\
(\uparrow \times \hat{0}, \text { family numbers } \\
\text { in parentheses })\end{array}$ & Comparison type & $\begin{array}{c}3 \mathrm{~h} \\
\text { samples }\end{array}$ & $\begin{array}{c}72 \mathrm{~h} \\
\text { samples }\end{array}$ \\
\hline$\times \mathrm{E}(1)$ vs $\mathrm{G} \times \mathrm{G}$ (3) & Pure vs pure & $0.130^{\text {ns }}$ & $0.803^{\text {ns }}$ \\
\hline (1) vs $\mathrm{E} \times \mathrm{G}$ (2) & ure vs hybrid & $0.191^{\text {ns }}$ & $0.061^{\mathrm{ns}}$ \\
\hline (1) vs $\mathrm{G} \times \mathrm{E}$ (4) & ure $v$ s hybrid & $1.000^{\mathrm{ns}}$ & $<0.001^{* *}$ \\
\hline $\mathrm{G}(3)$ (3) $\mathrm{E} \times \mathrm{G}(2)$ & ure vs hybrid & $0.005^{*}$ & $0.104^{\mathrm{ns}}$ \\
\hline $\mathrm{G} \times \mathrm{G}(3)$ vs $\mathrm{G} \times \mathrm{E}$ & Pure vs hybrid & $0.061^{\mathrm{ns}}$ & $<0.001^{* *}$ \\
\hline Г & & $0.474^{\mathrm{ns}}$ & $0.435^{\mathrm{n}}$ \\
\hline$E \times E(5)$ vs $E \times G(6)$ & Pure vs hybrid & $1.000^{\mathrm{ns}}$ & $0.005^{*}$ \\
\hline $\mathrm{E}(5)$ vs $\mathrm{G} \times \mathrm{E}(8)$ & are $v s$ hybrid & $1.000^{\mathrm{ns}}$ & $0.005^{*}$ \\
\hline $\mathrm{G}(7)$ vs $\mathrm{E} \times \mathrm{G}(6)$ & Pure $v s$ hybrid & $0.231^{\mathrm{ns}}$ & 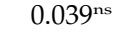 \\
\hline $\mathrm{G} \times \mathrm{G}(7)$ vs $\mathrm{G} \times \mathrm{E}$ & Pure vs hybrid & $0.474^{\mathrm{ns}}$ & $<0.001^{* *}$ \\
\hline & & $1.000^{\mathrm{ns}}$ & 0.120 \\
\hline $\mathrm{E} \times \mathrm{E}(9)$ vs $\mathrm{E} \times \mathrm{G}(10)$ & re vs hybrid & $0.490^{\mathrm{ns}}$ & 0.019 \\
\hline $\mathrm{E} \times \mathrm{E}(9)$ vs $\mathrm{G} \times \mathrm{E}$ & Pure vs hybrid & $0.479^{\text {ns }}$ & $<0.001^{* *}$ \\
\hline $\mathrm{G} \times \mathrm{G}(11)$ vs $\mathrm{E} \times \mathrm{G}(10)$ & & $0.490^{\mathrm{ns}}$ & $<0.001^{* *}$ \\
\hline $\mathrm{G} \times \mathrm{G}(11)$ vs $\mathrm{G} \times \mathrm{E}(12)$ & Pure $v s$ hybrid & $0.479^{\text {ns }}$ & $0.001 * *$ \\
\hline
\end{tabular}

$\mathrm{E}=M$. edulis, $\mathrm{G}=M$. galloprovincialis, $\mathrm{ns}$ indicates nonsignificant results, bold type indicates significant results: *at the 0.05 level and **at the 0.01 level after correction for multiple testing using the sequential Bonferroni method with $k=12$ for pure species $v$ s hybrid family comparisons (Holm, 1979; Rice, 1989).

likely the result of a higher frequency of PCR failure in this family.

At $72 \mathrm{~h}$, however, eight of the 12 pure species $v$ s hybrid family comparisons showed significant differences. These pure species $v s$ hybrid family comparisons can be grouped according to whether the two families being compared share the same female or male parent. The three comparisons involving $M$. galloprovincialis females crossed with males of both species (families 3 vs 4, 7 vs 8 and 11 vs 12), all show significant differences. The proportion of larvae with the $\mathrm{M}$ mitotype in the hybrid families is significantly lower than that in the pure species families, which demonstrates that when the female parent is $M$. galloprovincialis, the $M$. edulis $\mathrm{M}$ mitotype is eliminated more frequently than the $M$. galloprovincialis $\mathrm{M}$ mitotype. The comparisons of $M$. edulis females crossed with males of both species (1 vs 2, 5 vs 6 and 9 vs 10) suggest that the proportion of larvae with the $\mathrm{M}$ mitotype in the hybrid families is greater than that in the pure species families. The comparison between families 5 vs 6 shows a significant difference, and those between families 1 vs 2 and 9 vs 10 are approaching significance. These three comparisons were tested for overall significance using the 'combining probabilities from tests of significance' technique (Sokal and Rohlf, 1995). This technique combines the probabilities $(P)$ from a series of separate significance tests of the same hypothesis on different data sets. The $P$-values are transformed to give a quantity ' $-2 \Sigma \ln P^{\prime}$ which has a $\chi^{2}$ distribution with $2 k$ degrees of freedom, where $k$ is the number of separate $P$-values used. For the three comparisons in this case, $-2 \Sigma \ln P=24.117$ with six degrees of freedom, which is significant at the 0.001 level. This shows that when the female is M. edulis, the $M$. edulis $\mathrm{M}$ mitotype is eliminated significantly more frequently than the $M$. galloprovincialis $M$ mitotype. Where an M. edulis male is crossed with females of both species, the three comparisons (1 vs 4, 5 vs 8 and 9 vs 12) show that the proportion of larvae with the M mitotype is significantly lower in the hybrid family than in the pure species family. This suggests that the $M$. edulis $\mathrm{M}$ mitotype is eliminated more frequently by $M$. galloprovincialis females than by $M$. edulis females. Where an M. galloprovincialis male is crossed with females of both species, the data from the three comparisons ( 2 vs 3,6 vs 7 and 10 vs 11) suggest that the proportion of larvae with the $\mathrm{M}$ mitotype in the hybrid family is greater than in the pure species family, although only the family 10 vs 11 comparison is individually significant. The combined test (Sokal and Rohlf, 1995) described above shows the overall significance of the three comparisons at the 0.001 level $(-2 \Sigma \ln P=24.831,6$ d.f.). Thus, the $M$. galloprovincialis $\mathrm{M}$ mitotype is eliminated significantly less frequently by $M$. edulis females than by $M$. galloprovincialis females. Overall, the results show that, in hybrid families, the $M$. edulis $\mathrm{M}$ mitotype is eliminated more frequently, and the $M$. galloprovincialis $M$ mitotype is eliminated less frequently, than in pure species families.

\section{Discussion}

The results of the present study confirm that hybridization between $M$. edulis and M. galloprovincialis successfully produces larvae that survive until at least $72 \mathrm{~h}$ after fertilization, some of which have $F$ and $M$ mitotypes from different species. This is consistent with the widespread hybridization observed between these species in the wild (Skibinski et al, 1983; McDonald et al, 1991).

As the $\mathrm{M}$ mitotype was detected in nearly all 3-h-old larvae examined from the six hybrid families in this study, there is no evidence that hybridization disrupts the inheritance of the $\mathrm{M}$ mitotype. However, the results do suggest that hybridization between $M$. edulis and M. galloprovincialis may disrupt the normal regulation of elimination of the $\mathrm{M}$ mitotype. The differences in the proportion of 72-h-old larvae with the $M$ mitotype between pure species and hybrid families are indicative of the presence of M-negative males or M-positive females in the hybrid families. Differential mortality of hybrid males and females between 3 and $72 \mathrm{~h}$ could produce similar results (if reciprocal hybrid crosses were affected asymmetrically), but the overall hybrid viability does not appear to differ from that of pure species larvae at this development stage (see below). In some cases, we have data (not shown) for pre-72 h mortality in hybrid families suggesting that, even if differential mortality between males and females occurred, the overall mortality was not sufficient to account for the observed differences between pure species and hybrid families. Mpositive females and M-negative males have been observed in hybrid Mytilus populations in the wild and are thought to be associated with hybridization (Rawson et al, 1996).

The results of the present study are striking in two ways. First, the apparent frequency of DUI disruption observed in the present study appears to be far greater than the low levels detected in $M$. edulis $\times M$. galloprovincialis hybrid populations in the wild (Rawson et al, 1996). Second, the disruptions of DUI observed in the two types of hybrid cross are of a contrasting nature. In comparison to the pure species families, the proportion 
of 72-h-old larvae with the $\mathrm{M}$ mitotype is higher in the $M$. edulis female $\times M$. galloprovincialis male families, which suggests the presence of M-positive females in these families. However, in the M. galloprovincialis female $\times M$. edulis male families, the proportion of 72-hold larvae with the $\mathrm{M}$ mitotype is much lower, indicating that these families contain M-negative males.

To assess the extent of the disruption of DUI in the hybrid families, it is necessary to make three assumptions: firstly that the sex ratio is identical in each pair of pure species and hybrid families that have the same mother, secondly that the proportion of pure species larvae with the $\mathrm{M}$ mitotype is equal to the proportion of males, and finally that there is no differential mortality of male or female hybrids between 3 and $72 \mathrm{~h}$. The validity of these assumptions has already been discussed (see above). The expected number of each sex can then be calculated for the hybrid families and hence, the number of putative M-positive females and M-negative males can be deduced. From the six hybrid families in the present study, it appears that $36 \%$ of hybrid larvae expected to be females were M-positive and that $39 \%$ of those expected to be males were M-negative (calculated as an average for all larvae in the six hybrid families). It may be that both M-negative males and M-positive females are present in one or more of these families, but this cannot be confirmed because as yet we have no means of determining the sex of a larva. The presence of both forms of DUI breakdown in equal numbers in a family would cancel out any effect on the proportion of larvae with the $\mathrm{M}$ mitotype; therefore, the assumption that any differences in this proportion are produced by the presence of only one form of breakdown will give minimal estimates of the frequency of DUI breakdown.

The level of disruption observed in hybrid larvae from these laboratory crosses is more than double that previously found in adult mussels from natural M. edulis $\times M$. galloprovincialis hybrid populations (Rawson et al, 1996). These authors examined 25 female and 36 male $M$. edulis $\times M$. galloprovincialis adult hybrids from Whitsand Bay (UK), of which $54 \%$ had putative $\mathrm{F}_{1}$ genotypes at three informative allozyme loci, and found only one M-positive female (4\% of females) and four Mnegative males ( $11 \%$ of males). Even if it is assumed that all of the observed disruptions occurred in putative $F_{1}$ mussels (this was not stated), the percentage of adult $F_{1}$ individuals showing disruption of DUI is only $15 \%$, compared to $38 \%$ estimated from the $\mathrm{F}_{1}$ hybrid 72 -h-old larvae in the present study.

It was previously assumed that either disruptions of DUI were very rare in $M$. edulis $\times M$. galloprovincialis hybrids, or that individuals with disrupted DUI rarely survived to adulthood. The difference between the results obtained from larvae (this study) and from adults (Rawson et al, 1996) suggests that hybrid individuals in which DUI has been disrupted might suffer greater mortality between $72 \mathrm{~h}$ and adulthood than mussels in which DUI has not been disrupted. There is evidence from a number of studies that adult $M$. edulis $\times M$. galloprovincialis hybrids on average have a fitness approximately equal to $M$. galloprovincialis and higher than M. edulis, in terms of viability (Gardner and Skibinski, 1991; Willis and Skibinski, 1992; Gardner et al, 1993), developmental stability and developmental rate
(Gardner, 1995), growth rate (Gardner et al, 1993), fertility and fecundity (Gardner and Skibinski, 1990) and resistance to parasites (Coustau et al, 1991). Previous studies of laboratory hybridizations between $M$. edulis and M. galloprovincialis showed no difference in the viability of early (up to 2 or 3 days) hybrid larvae compared to pure species larvae (Beaumont et al, 1993; Bierne et al, 2002; our unpublished data). However, hybrid veliger larvae did have significantly lower viability than pure species larvae between 3 and 16 days (Beaumont et al, 1993) or between 2 and 35 days (Bierne et al, 2002). Interestingly, the hybrid larvae that did survive grew significantly faster than the pure species larvae (Beaumont et al, 1993; Bierne et al, 2002). It may be that there is considerable variation in the fitness of hybrid $M$. edulis $\times M$. galloprovincialis mussels and only those that have relatively high fitness survive to adulthood to be analysed in studies of natural populations, whereas those with lower fitness suffer early mortality.

Alternatively, it could be that DUI disruptions occur more frequently in laboratory crosses than in nature, but there is currently no evidence for this. DUI has not been previously studied in hybrid larvae and there is insufficient evidence to conclude whether the high levels of DUI disruption observed in the present study are a feature of laboratory crosses or whether disruption of DUI is associated with increased mortality. It should be noted that the parent mussels used in the present study were from populations separated by greater geographical distance (M. edulis from Scotland and M. galloprovincialis from the Mediterranean Sea) than is conceivable for the parents of the putative $F_{1}$ hybrid mussels examined by Rawson et al (1996), which came from an area of natural hybridization. Also, Rawson et al (1996) inferred $F_{1}$ status from three nearly diagnostic allozyme loci, but it is possible that these mussels were actually offspring from matings between backcross individuals. These factors might result in a lower probability of any incompatibility responsible for disruption of DUI occurring in the hybrids in the study of Rawson et al (1996), compared with that existing between the pure M. edulis and $M$. galloprovincialis used in the present study. Further laboratory crosses between $M$. edulis and M. trossulus and between $M$. galloprovincialis and $M$. trossulus are necessary to facilitate direct comparison of the extent to which DUI is disrupted in hybrids of these species.

The disruption of DUI observed in the three M. galloprovincialis female $\times M$. edulis male families in the present study, where $81 \%$ of larvae expected to be males did not contain the $\mathrm{M}$ mitotype, has the potential to limit introgression of the $M$. edulis $M$ mitotype into M. galloprovincialis. Widespread introgression of $M$. edulis F mitotypes into Mediterranean $M$. galloprovincialis populations has been detected by Rawson and Hilbish (1998), but introgression of $M$. edulis M mitotypes appeared to be less prevalent. The findings of the present study offer a possible explanation for this in the form of disruption to the retention of the M. edulis $\mathrm{M}$ mitotype in hybrids. In contrast, the present study provides no evidence for disruption of DUI limiting the introgression of the M. galloprovincialis M mitotype into $M$. edulis. The results from the three $M$. edulis female $\times M$. galloprovincialis male crosses in the present study do not reveal any presence of $\mathrm{M}$-negative male offspring, and the $\mathrm{M}$ 
mitotype was detected in $66 \%$ of larvae expected to be females. Rawson and Hilbish (1998) failed to find evidence of mtDNA introgression from Mediterranean $M$. galloprovincialis to $M$. edulis, and suggested that directional selection favouring $M$. galloprovincialis nuclear alleles over those of $M$. edulis might remove those hybrid mussels with predominantly $M$. edulis nuclear genotypes. Such selection has been shown to occur in hybrid populations (Gardner and Skibinski, 1988, 1991; Skibinski and Roderick, 1991; Gardner et al, 1993) and would have the effect of removing potentially introgressing $M$. galloprovincialis mitotypes but not those of $M$. edulis. Further studies would be necessary to determine whether either of these factors plays a significant role in restricting gene flow between $M$. edulis and M. galloprovincialis.

The present study demonstrates that hybridization between M. edulis and M. galloprovincialis does not affect the inheritance of the $M$ mitotype at fertilization. Although the sex of a larva cannot be determined and hence the presence of M-negative males or M-positive females cannot be confirmed, the findings of the present study suggest that occurrences of both M-negative males and M-positive females are associated with hybridization, but that the two forms of disruption to DUI do not necessarily occur in the same proportions in reciprocal hybrid crosses. This provides further support for the hypothesis that the regulation of DUI involves a complex system of interactions that control the retention of the $\mathrm{M}$ mitotype in males independently from its elimination in females (Saavedra et al, 1997). It appears that disruption of DUI in hybrids may limit introgression, both directly by increased elimination of the $M$. edulis $M$ mitotype in hybrids, and indirectly, if disruption of DUI is associated with reduced hybrid viability. However, disruption of DUI cannot be the only factor limiting introgression between $M$. edulis, M. galloprovincialis and $M$. trossulus. It is likely that a range of both genetic and environmental factors are important in determining the location and extent of hybrid zones and hence in the maintenance of genetic integrity for the three species.

\section{Acknowledgements}

We thank J-P Cadoret and J Holmyard for providing us with mussels and M Budd for provision of algal foods. We also thank J Latchford for helpful discussions and two anonymous referees for their suggestions. This research was funded by the Natural Environment Research Council (Grant GR3/11335 to ARB and DOFS).

\section{References}

Barton NH, Hewitt GM (1989). Adaptation speciation and hybrid zones. Nature 341: 497-503.

Beaumont AR, Abdul-Matin AKM, Seed R (1993). Early development survival and growth in pure and hybrid larvae of Mytilus edulis and M. galloprovincialis. J Molluscan Stud 59: 120-123.

Bierne N, David P, Boudry P, Bonhomme F (2002). Assortative fertilization and selection at larval stage in the mussels Mytilus edulis and M. galloprovincialis. Evol Int J Org Evol 56: 292-298.
Coustau C, Renaud F, Maillard C, Pasteur N, Delay B (1991). Differential susceptibility to a trematode parasite among genotypes of the Mytilus edulis/galloprovincialis complex. Genet Res 57: 207-212.

Gardner JPA (1994). The structure and dynamics of naturally occurring hybrid Mytilus edulis Linnaeus 1758 and Mytilus galloprovincialis Lamarck 1819 (Bivalvia: Mollusca) populations - review and interpretation. Arch Hydrobiol 99: 37-71.

Gardner JPA (1995). Developmental stability is not disrupted by extensive hybridization and introgression among populations of the marine bivalve molluscs Mytilus edulis and Mytilus galloprovincialis from SW England. Biol J Linn Soc Lond 54: 71-86.

Gardner JPA, Skibinski DOF (1988). Historical and sizedependent genetic variation in hybrid mussel populations. Heredity 61: 93-105.

Gardner JPA, Skibinski DOF (1990). Genotype-dependent fecundity and temporal variation of spawning in hybrid mussel populations. Mar Biol 105: 153-162.

Gardner JPA, Skibinski DOF (1991). Biological and physical factors influencing genotype-dependent mortality in hybrid mussel populations. Mar Ecol Progr Ser 71: 235-243.

Gardner JPA, Skibinski DOF, Bajdik CD (1993). Shell growth and viability differences between the marine mussels Mytilus edulis (L.), Mytilus galloprovincialis (Lmk.) and their hybrids from two sympatric populations in S.W. England. Biol Bull 185: 405-416.

Garrido-Ramos MA, Stewart DT, Sutherland BW, Zouros E (1998). The distribution of male-transmitted and female transmitted mitochondrial DNA types in somatic tissues of blue mussels: implications for the operation of doubly uniparental inheritance of mitochondrial DNA. Genome 41: 818-824.

Gosling EM (1992). Systematic and geographic distribution of Mytilus. In: Gosling EM (ed) The Mussel Mytilus: Ecology, Physiology, Genetics and Culture. Elsevier Science Publishers: Amsterdam. pp 1-20.

Holm S (1979). A simple sequentially rejective multiple test procedure. Scand J Stat 6: 56-70.

Inoue K, Waite JH, Matsuoka M, Odo S, Harayama S (1995). Interspecific variations in adhesive protein sequences of Mytilus edulis, M. galloprovincialis and M. trossulus. Biol Bull 189: 370-375.

Kenchington E, MacDonald B, Cao L, Tsagkarakis D, Zouros E (2002). Genetics of mother-dependent sex ratio in blue mussels (Mytilus spp.) and implications for doubly uniparental inheritance of mitochondrial DNA. Genetics 161: 1579-1588.

Longo FJ, Anderson E (1969). Cytological aspects of fertilisation in the lamellibranch Mytilus edulis 2. Development of the male pronucleus and the association of the maternally and paternally derived chromosomes. J Exp Zool 172: 97-120.

Lubet P, Prunus G, Masson M, Bucaille D (1984). Recherches expérimentales sur l'hybridation de Mytilus edulis et $M$. galloprovincialis. Bull Soc Zool France 109: 87-99.

McDonald JH, Seed R, Koehn RK (1991). Allozymes and morphometric characters of three species of Mytilus in the Northern and Southern hemispheres. Mar Biol 111: 323-333.

Rawson PD, Hilbish TJ (1995). Distribution of male and female mtDNA lineages in populations of the blue mussels Mytilus trossulus and $M$. galloprovincialis along the Pacific coast of North America. Mar Biol 124: 245-250.

Rawson PD, Hilbish TJ (1998). Asymmetric introgression of mitochondrial DNA among European populations of blue mussels (Mytilus spp.). Evol Int J Org Evol 52: 100-108.

Rawson PD, Secor CL, Hilbish TJ (1996). The effects of natural hybridization on the regulation of doubly uniparental mtDNA inheritance in blue mussels (Mytilus spp.). Genetics 144: $241-248$ 
Rice WR (1989). Analyzing tables of statistical tests. Evol Int J Org Evol 43: 223-225.

Saavedra C, Reyero M-I, Zouros E (1997). Male-dependent doubly uniparental inheritance of mitochondrial DNA and female-dependent sex-ratio in the mussel Mytilus galloprovincialis. Genetics 145: 1073-1082.

Saavedra C, Stewart DT, Stanwood RR, Zouros E (1996). Species-specific segregation of gender-associated mitochondrial DNA types in an area where two mussel species (Mytilus edulis and M. trossulus) hybridize. Genetics 143: 1359-1367.

Sambrook J, Fritsch EF, Maniatis T (1989). Molecular Cloning: A Laboratory Manual. Vols 1-3, 2nd edn. Cold Spring Harbor Press: New York.

Sanjuan A, Zapata C, Alvarez G (1994). Mytilus galloprovincialis and M. edulis on the coasts of the Iberian Peninsula. Mar Ecol Progr Ser 113: 131-146.

Skibinski DOF, Beardmore JA, Cross TF (1983). Aspects of the population genetics of Mytilus (Mytilidae: Mollusca) in the British Isles. Biol J Linn Soc Lond 19: 137-183.

Skibinski DOF, Gallagher C, Beynon CM (1994). Sex-limited mitochondrial DNA transmission in the marine mussel Mytilus edulis. Genetics 138: 801-809.

Skibinski DOF, Roderick EE (1991). Evidence of selective mortality in favour of the Mytilus galloprovincialis Lmk. phenotype in British mussel populations. Biol J Linn Soc Lond 42: 351-366.

Sokal RR, Rohlf FJ (1995). Biometry: The Principles and Practice of Statistics in Biological Research. 3rd edn. WH Freeman and Company: New York.

Stewart DT, Saavedra C, Stanwood RR, Ball AO, Zouros E (1995). Male and female mitochondrial DNA lineages in the blue mussel (Mytilus edulis) species group. Mol Biol Evol 12: 735-747.

Sutherland B, Stewart D, Kenchington ER, Zouros E (1998). The fate of paternal mitochondrial DNA in developing female mussels Mytilus edulis: implications for the mechanism of doubly uniparental inheritance of mitochondrial DNA. Genetics 148: 341-347.

Willis GL, Skibinski DOF (1992). Variation in strength of attachment to the substrate explains differential mortality in hybrid mussel (Mytilus galloprovincialis and Mytilus edulis) populations. Mar Biol 112: 403-408.

Wood AR, Beaumont AR, Skibinski DOF, Turner G (2003). Analysis of a nuclear DNA marker for species identification of adults and larvae in the Mytilus edulis complex. J Molluscan Stud 69: 61-66.

Zouros E, Ball AO, Saavedra C, Freeman KR (1994). An unusual type of mitochondrial DNA inheritance in the blue mussel Mytilus. Proc Natl Acad Sci USA 91: 7463-7467. 